\title{
Do Payment Mechanisms Change the Way Consumers Perceive Products?
}

\author{
PROMOTHESH CHATTERJEE \\ RANDALL L. ROSE
}

\begin{abstract}
Do payment mechanisms change the way consumers perceive products? We argue that consumers for whom credit cards (cash) have been primed focus more on benefits (costs) when evaluating a product. In study 1, credit card (cash) primed participants made more (fewer) recall errors regarding cost attributes. In a word recognition task (study 2), participants primed with credit card (cash) identified more words related to benefits (costs) than those in the cash (credit card) condition. In study 3 , participants in the credit card (cash) condition responded faster to benefits (costs) than to costs (benefits). This differential focus led credit card primed consumers to express higher reservation prices (studies 1-3) and also affected their product choices (study 4 ) relative to those primed with cash.
\end{abstract}

$\mathrm{T}^{\mathrm{s}}$ he use of a credit card as a payment mechanism increases the propensity to spend as compared to cash in otherwise identical purchase situations (Feinberg 1986; Hirschman 1979; Prelec and Simester 2001; Soman 2001; Soman and Cheema 2002), a finding typically referred to as the credit card premium. While prior research has explained the spending effects of different payment mechanisms by attributing them to memory processes (Soman 2001), decoupling of purchase from the pain of payment (Prelec and Loewenstein 1998), classical conditioning (Feinberg 1986), and processing fluency (Mishra, Mishra, and Nayakankuppam 2006), they remain silent as to consumers' product evaluations and choices. It is implicit in this stream of research that the product intended for purchase is perceived and evaluated the same way across different payment mechanisms.

We take a fresh look at the credit card premium and argue

Promothesh Chatterjee is assistant professor of marketing at the KU School of Business, University of Kansas, 1300 Sunnyside Avenue, Lawrence, KS 66045-7585, e-mail: chatterjee@ku.edu. Randall L. Rose is chair and professor of marketing, Moore School of Business, University of South Carolina, 1705 College Street, Columbia, SC 29208, e-mail: roser@moore.sc.edu. The authors contributed equally, and names are listed in alphabetical order. The authors would like to thank Stacy Wood King, Caglar Irmak, Terry Shimp, Tom Kramer, Ashwani Monga, the editor, the associate editor, and three reviewers for their helpful comments and suggestions at various stages of this research.

Debbie MacInnis served as editor and Pierre Chandon served as associate editor for this article.

Electronically published August 11, 2011 that consumers' perception and evaluation of the products under consideration differ across payment mechanisms, more specifically, credit card and cash. That is, consumers who vary in terms of the salience of various payment mechanisms at the time of product evaluation and choice evaluate the same product in fundamentally different ways- the attention they allocate to different product features varies significantly. When credit cards as a payment mechanism are more accessible, consumers attend more to a product's benefits relative to the cost aspects of the product. Conversely, when cash as a payment mechanism is more accessible, consumers attend more to cost aspects of the product (broadly defined to include price, delivery time/costs, warranty costs, installation costs, etc.) relative to product benefits.

In three experiments, we find that consumers primed with credit card as a payment mechanism make more recall errors with respect to cost-related aspects of the product than to benefit aspects (study 1), identify more words related to benefits (study 2), and respond faster to benefit-related words (study 3 ) than consumers primed with cash concepts. In a fourth experiment, we extend this payment prime effect to product choice, by showing that credit-primed consumers are more likely to choose an option that offers superior benefits than those primed with cash, but cash-primed consumers are more likely to choose an option that dominates on costs, even when that option offers inferior benefits. Further, in this study, we reverse this payment prime effect by exposing consumers to a choice set decoy that is dominated on either cost or benefit considerations by one of the brands in the choice set (a manipulation that heightens the salience of cost/benefit dimensions). 
The remainder of the manuscript is organized in the following way: first, we review the literature relevant to use of credit cards versus cash in consumption, then we build our argument for payment mechanism effects on attention to product costs and benefits. Next, we test our predictions across four studies. We conclude with a discussion about the theoretical and practical implications of this research and suggest avenues for future research.

\section{THEORETICAL BACKGROUND}

\section{Payment Mechanisms and Spending Behavior}

The notion that spending behavior is influenced by payment mechanisms is not new. Hirschman (1979) reported a significant difference in the spending amounts when the preferred mode of payment was a credit card as opposed to other payment mechanisms. Subsequently, Feinberg (1986) demonstrated a substantial increase in spending and donation amounts by merely exposing the participants to credit card paraphernalia, that is, the participants in the credit card condition had a MasterCard logo placed on the desk where they were participating in the study. Later studies (Prelec and Simester 2001; Soman 2001) have addressed a few methodological issues existing in prior research and further supported the notion that the use of credit cards leads to increased willingness to spend and greater spending amounts. Though prior research does strengthen the idea that credit cards facilitate spending, the reasons underlying this effect need further clarification. For example, the classical conditioning explanation (Feinberg 1986) is based on the notion that credit cards act as purchase cues through repeated association with product purchases, but this explanation has been criticized on various grounds (Hunt et al. 1990; Shimp and Moody 2000). An important alternative explanatory concept related to the credit card premium is the "pain of payment." Spending behavior is affected by the extent to which pain of payment is felt when parting with money (Prelec and Loewenstein 1998). Payments with cash leave a vivid memory trace and are more punishing as the pain of payment is reinforced every time a transaction takes place. However, credit card purchases require only a signature, and hence the pain of payment is of a lower intensity. Thus, prior research seems to suggest that cash payments as opposed to payments with other formats elicit maximum pain of payment.

Extending the notion of pain of payment, Soman (2001) offers a memory-based explanation for the credit card premium involving retrospective evaluation of payments. Since credit card payments are low in salience and vividness, there is an underestimation of past expenses, leading to increased spending relative to the cash mechanism. Soman (2001) speculates that this explanation probably would not hold for high-priced products, as the payment in that case would have a greater salience because of the pain of payment associated with them (Prelec and Loewenstein 1998).

Thus, the mechanics of credit card as a payment method are such that it facilitates a decoupling of costs from benefits because the painful impact of payment is not immediate. In fact, Prelec and Loewenstein (1998) suggest that the more the payments can be psychologically "decoupled" from the consumption, the less they will reduce enjoyment and the better the overall assessment of the value of the transaction and vice versa. We extend this notion by arguing that consumers' ubiquitous use of credit cards reduces the salience of cost attributes at the product or service evaluation stage in many product or service purchase contexts. Initial use of the product is not as closely associated with the pain of payment because credit card payments are deferred for a few weeks after purchase in most instances. Thus, ubiquitous experience with credit cards reduces the strength of the association of costs with the products purchased and the payment method used. Further, consumers' experiences of instant gratification of desire when paying with a credit card and invoking a buy-now-pay-later mentality (Mendoza and Pracejus 1997; Shimp and Moody 2000) strengthen the associations between credit cards and the desired benefits. With repeated credit card purchase experiences ending in immediate gratification of desires, it is plausible that this can result in a greater accessibility of benefit considerations relative to cost considerations, especially in contexts where credit cards are commonly used.

However, with respect to cash payment, we suggest greater attention to the costs of the products under consideration. Cash payments are tightly "coupled" and have high salience and vividness and the highest pain of payment compared to other mechanisms (Prelec and Loewenstein 1998; Soman 2001). Cash payments have high psychological salience, as they involve handing over a visible amount of cash, driving home the fact that the benefits are being paid for. Having experienced the greater pain of payment when using cash in many prior transactions, consumers using the cash payment method to obtain a product or service (or for whom cash payment is primed) are more likely to attend to cost considerations and less likely to attend to product benefits than those paying with a credit card (or for whom credit cards are primed). This process in turn could strengthen the associations between cash as a payment method and the costs associated with the products purchased, especially for those who chronically pay with cash or in those situations where cash payments are the norm or strongly primed.

\section{Conceptualization}

Because there are likely to be clear differences in the associative networks surrounding credit card payments and cash payments, we conclude that attention to dramatically different informational inputs can be induced through a straightforward priming mechanism involving credit cards or cash (Bargh 2006; Fitzsimons, Chartrand, and Fitzsimons 2008). This activation of different associations in memory biases the processing of subsequently encountered stimuli in predictable ways (Bodenhausen 1988; Darley and Gross 1983). For example, Bodenhausen (1988) argues that the activation of a mental concept may lead to differential processing of subsequently encountered stimulus, depending on 
its consistency with the implications of the activated concept. Evidence that is consistent with the activated concept may receive more attention and rehearsal and may therefore be much more likely to be incorporated into the decision maker's mental representation of the scenario compared to inconsistent information. In a similar vein, we argue that priming credit cards directs attention to product benefits during subsequent initiation of a product evaluation task, while priming cash directs attention to cost aspects. These priming effects lead to differences in reservation price for products under consideration and also affect product choices. Recent empirical findings corroborate our thinking. For example, Laran, Dalton, and Andrade (2011) find that priming brands such as Walmart, whose positioning is strongly associated with thrift and savings, increases consumers' cost consciousness and subsequently reduces their spending intentions.

Because the cash and credit card payment mechanisms direct attention to different product features, attitudes toward the products being evaluated could be based on different types of considerations. Further, attitudes toward any one product could vary because the informational inputs to which consumers attend may differ depending on the payment mechanism that is primed. This is a key insight emerging from our work that has not been addressed in previous work related to the credit card premium.

We manipulate payment primes directly in our laboratory studies, but a variety of contextual or individual consumer factors that may be operating in a product purchase situation (Shiv and Huber 2000) can make either cash or credit card payment mechanisms more accessible to consumers and, in turn, increase attention to product benefits or costs. These factors may include the presence of credit card stimuli in advertisements, at store entrances, or at the point of purchase. For example, McDonald's recently ran a print advertisement that contained only a single tagline, the McDonald's logo, and a string of credit card logos at the bottom of the page. Other potential triggers include a preexisting intention to use cash or credit or the suggestion of a salesperson.

Next, we present three studies that test our explanation for payment mechanism effects. In study 4 , we extend the effect of payment prime to product choice and also demonstrate that the payment prime effect can be attenuated or even reversed. We create this moderation effect by shifting attention to either costs (in the credit card condition) or benefits (in the cash prime condition). We do this by introducing a decoy product to the choice set that is dominated on either costs or benefits by one of the other products in the choice set.

\section{STUDY 1: DIFFERENTIAL ERRORS DUE TO PAYMENT PRIMES}

The main objective of this experiment was to assess whether participants primed with credit card concepts allocate attention to different aspects of the products under consideration compared to participants primed with cash concepts. We have argued that credit card primes direct attention to benefit considerations whereas cash primes direct attention to costs. One way to understand the resources allocated to processing one aspect of a stimulus or another is to conduct an error analysis. Toward this end, we used probes to examine memory traces and information structure (Anderson 1983; Anderson and Gordon 1973). If the participants primed with credit card concepts do attend more closely to benefit considerations than the costs, they would be more likely to make errors when questioned about the costs and vice versa for the participants primed with the cash concepts.

\section{Method and Design}

Pretest of Payment Manipulation. Following the suggestions of Bargh and Chartrand (2000), we asked 56 participants to generate five words related to cash or credit cards in a separate pretest. The objective of this pretest was to identify words participants associate with the different payment methods. Only the words that occurred at least five times were subsequently used in a sentence-scrambling task to prime the concepts associated with the payment methods.

Study Details. Fifty-nine undergraduates participated in the experiment for partial course credit, in full compliance with institutional policies regarding student participation in research. The study was developed for use on personal computers through MediaLab software. The computer informed participants that they would be participating in a word test. The participants were randomly assigned to either a cash condition or a credit card condition. Participants initially engaged in a sentence-unscrambling task, adapted from Bargh and Chartrand (2000), in which they constructed grammatically correct sentences using four words from a list of five scrambled words. For those in the credit card condition, words invoking credit-card-related concepts were embedded in the list (e.g., "TV shall watch we Visa"; the solution for which is "we shall watch TV"). Similarly, for those in the cash condition, words invoking cash-related concepts were used (e.g., "TV shall watch we ATM"). The unscrambling tasks also involved making sentences with some neutral words.

After the sentence-unscrambling task, the participants were shown a picture of a camera. Subsequently, they were alternately shown three benefits and three cost features (costs were financial, and benefits were product attribute related) one by one on different screens ([1] The camera has a $12 \times$ optical zoom for high magnification; [2] The suggested retail price of the camera is $\$ 367.77$; [3] 8 megapixels CCD captures high-resolution images for better picture quality; [4] 2 years warranty costs an additional \$69.99; [5] High-resolution 3.5-inch vari-angle LCD for easy shooting at any angle; [6] Optional rechargeable battery kit is available for $\$ 37.50)$. After this, the participants indicated their reservation prices. In the next phase of the experiment, the participants engaged in a short filler task. Next, the participants were shown the same features of the camera as they had 
seen earlier but in a true or false form, for example, "The camera has a $10 \times$ optical zoom for high magnification." The participants were then asked to make true/false judgments. Error rate was the dependent variable. It was hypothesized here that there would be a systematic difference in the error rates between the consumers primed with the credit card concepts versus those primed with cash concepts. Credit card consumers should show a higher error rate for costs and lower error rate for benefits compared to the cash payers because of their differential processing, implying a payment format $\times$ feature interaction.

\section{Results}

Credit Card Premium. We ran an ANOVA with reservation price as the dependent variable and payment method as the between-subjects factor. Consistent with the notion of a credit card premium that has been demonstrated in prior research, on average a greater reservation price emerged in the credit card condition than in the cash condition $\left(M_{\text {credit }}\right.$ $=\$ 364.99$ vs. $\left.M_{\text {cash }}=\$ 312.49 ; F(1,57)=3.88, p<.05\right)$.

Error Analysis. A repeated measures approach with probit analysis was used to analyze errors as a function of payment condition and features (Agresti 2002). The payment $\times$ feature interaction was marginally significant (Wald $\chi^{2}$ $=3.35, p=.06$ ). Further analyses revealed that there were systematic errors across the benefits and costs. Participants primed with credit card concepts made more errors with respect to the cost attributes $(12.9 \%)$ than the cash-primed participants whose error rate was $7.1 \%\left(\chi^{2}=3.86, p<.05\right)$. For the benefit attributes, error rates did not differ significantly. The error rate for credit-card-primed participants was $6.99 \%$ compared to $8.93 \%$ for the cash-primed participants $\left(\chi^{2}=0.47, p=.46\right.$; see fig. 1$)$.

\section{Discussion}

The results of this experiment provide some evidence relevant to our hypothesis that consumers attend to different product features during evaluation when primed with different payment methods. Priming credit cards led to greater recall errors with respect to cost attributes compared to priming cash. This result suggests that the credit card prime reduced attention to the cost aspects of the product relative to the cash prime. However, the priming manipulation did not significantly affect error rates with respect to recall of product benefits, suggesting that the priming manipulation did not affect thinking about benefits as strongly as expected. Although the error proportions were in the expected direction, error rates for benefits did not differ significantly, perhaps reflecting a floor effect. Error rates were generally low. It is possible that a longer time delay between exposure to the product descriptions and the attribute recognition task would have revealed significant differences. In the next study, we provide stronger evidence toward our thesis by using a different approach to assess the nature of cognitive processes after being primed with payment mechanisms.

\section{FIGURE 1}

STUDY 1: DIFFERENTIAL ERRORS DUE TO PAYMENT PRIMES

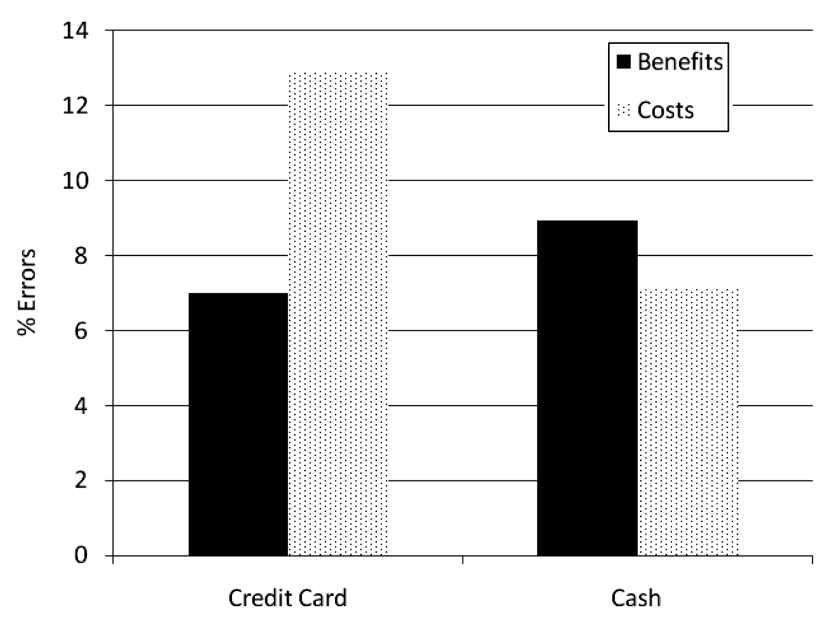

\section{STUDY 2: EVIDENCE FROM A LEXICAL TASK}

The main objective of this study was to provide a different yet rigorous examination of the nature of consumers' thinking when evaluating a product following a payment mechanism prime. An important piece of evidence in favor of our priming explanation would be obtained if participants respond to a benefit-based versus cost-based lexical task differently. More specifically, credit-card-primed participants should identify more words related to product benefits than words related to costs relative to those in the cash condition.

\section{Method and Design}

One-hundred and four undergraduates participated in the experiment for partial course credit, in full compliance with institutional policies regarding student participation in research. The participants were seated in separate cubicles that had computers for the purpose of the study. In accordance with our objective, the participants were randomly divided into credit card condition or cash condition. Similar to our previous study, we primed the different conditions using a sentence-unscrambling task. The participants next saw a picture of Asus netbook with reviews from the editor of CNET.com that included both the benefit attributes as well as the cost attributes. It is important to note here that costs were not only financial but included other aspects related to functionality as well (such as custom interface that requires a learning curve, small screen that makes reading difficult, tiny hard drive that limits storage capacity, and less powerful version of Intel processor). Subsequently, we elicited the reservation price for the product.

This was followed by a word recognition study (Lee and 
Aaker 2004) that was ostensibly unrelated to the product evaluation task. The participants were told that some words would flash very quickly on the computer screen one at a time, followed by a series of "\#” signs. The participants were to type in the word they think they saw. If the participants could not see anything, they were asked to guess what the word might be. Words flashed at the middle of the screen for 200 milliseconds and were backward-masked (i.e., followed by a series of "\#\#\#\#”). Some of these words were taken from the Asus review, and others were neutral words. A total of 12 words were flashed randomly, four related to benefits, four to costs, and four neutral. The idea here was that participants in the credit card condition would be able to recognize more words related to benefits than costs, and vice versa for the participants in the cash condition. Finally, the participants answered questions related to mood, involvement, and demographics.

\section{Results}

Credit Card Premium. Mood, involvement, and demographics did not influence the results. A one-way ANOVA with payment primes as independent variable and reservation price as dependent variable was performed. Consistent with a credit card premium, we found a main effect of payment prime $\left(M_{\text {credit }}=\$ 702.94\right.$ vs. $M_{\text {cash }}=\$ 586.28 ; F(1$, 100) $=5.33, p<.05)$.

Word Recognition. A repeated-measures analysis with target word type (positive vs. negative) as the within-participant factor and payment prime as the between-participant factor was performed. This resulted in a word type $\times$ payment mechanism interaction $(F(1,100)=13.74, p<.001)$. Specifically, people in the credit card condition identified more words related to benefits than those in the cash condition $\left(M_{\text {credit }}=3.77\right.$ vs. $\left.M_{\text {cash }}=3.51 ; p<.05\right)$, while those in the cash condition identified more words related to costs than benefits $\left(M_{\text {credit }}=3.49\right.$ vs. $M_{\text {cash }}=3.77, p<.05$; see fig. 2). There was no effect of the payment primes on the neutral words.

\section{Discussion}

Using a very different dependent measure of the target of attention, we again find results supporting the biased processing explanation. Participants in the credit card condition identify more words related to benefits than those in the cash condition, whereas participants in the cash condition identified more words related to costs than benefits. In study 3, we provide further process evidence by assessing response latencies as the focal dependent variable.

\section{STUDY 3: MEDIATION BY RESPONSE LATENCY}

One major objective of the study was to provide further evidence toward our proposed theoretical process by as-
FIGURE 2

\section{STUDY 2: DIFFERENTIAL FOCUS DUE TO PAYMENT PRIMES}

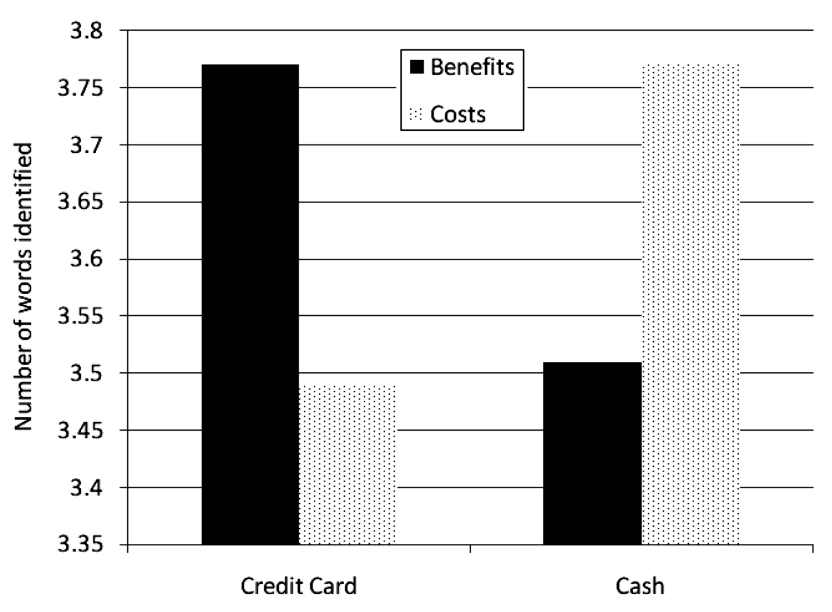

sessing response latencies. If costs are allocated greater attention when cash payments are accessible and benefits with credit card payments, cash-primed participants should respond faster to the costs of a product being evaluated, and credit-card-primed participants should respond faster to the benefits. In this way, we sought to replicate the results of study 2 with a different criterion variable. In our first two studies, the payment mechanism effect was assessed in the context of an immediate choice or purchase. However, because purchases with credit cards are decoupled temporally from the pain of payment relative to cash payments, it is possible that a different temporal framing of the prospective purchase (i.e., immediate vs. delayed) may change the results. Thus, another objective of this study was to test the robustness of the credit card payment effects in a delayed purchase context.

\section{Method and Design}

One hundred and thirty-four students participated in a computer-assisted study for partial course credit through a departmental subject pool, in full compliance with institutional policies governing student participation in research. The study was developed for use on personal computers through MediaLab software. The participants were randomly assigned to the credit card or cash condition and performed the sentence-unscrambling task similar to the previous studies. Participants were then informed that they would be shown a product that they were interested in purchasing now versus after 1 month in the near versus later condition.

The participants were shown a picture of an iPhone with reviews from the editor of CNET.com that included both the positives as well as the negatives. The study was a 2 (prime: credit card vs. cash) $\times 2$ (time: now vs. later) be- 
tween-participants design. The order of price elicitation and response latency tasks was counterbalanced. After the participants saw the iPhone and read its review, they were directed to a response latency task. In the response latency task, the participants were informed that they had to classify different features as costs versus benefits as quickly as possible. They were told that costs need not only be financial but can also include things like friends' disapproval of the product or difficulty of use. Similarly, the participants were informed that benefits need not be restricted to product features only; they may include things like social prestige or enhancement of self-image. Thus, costs were financial, functional, and social, and the benefits were functional and social. If costs were salient to cash-primed participants, they would identify these quickly whereas the credit-card-primed participants would identify benefits quickly if those were salient to them. Participants were told to press "P" if a feature is related to benefits and press " $Q$ " if the feature is related to costs. Words related to costs and benefits flashed on the screen one by one in a random order. After the response latency task, participants indicated their reservation price.

\section{Results}

Credit Card Premium. An ANOVA was conducted with payment prime, time of purchase, and their interacting variables as predictors, and reservation price as the dependent variable. Consistent with the notion of credit card premium, there was a significant main effect of payment prime on reservation price $\left(M_{\text {credit }}=\$ 205.12\right.$ vs. $M_{\text {cash }}=\$ 163.40$; $F(1,130)=12.48, p<.001)$. None of the other factors were significant predictors.

Response Latency. Consistent with prior research using such indirect measures (Mishra 2009), an overall benefit score $\left(\mathrm{S}_{\mathrm{b}}\right)$ was calculated for each participant by averaging the response times for the benefit words. Similarly, an overall cost score $\left(\mathrm{S}_{\mathrm{c}}\right)$ was calculated for each participant by averaging the response times for the cost words. Finally, a single measure was calculated for each participant by subtracting the response time for benefit words from the response time for cost words $\left(S_{c}-S_{b}\right)$. A difference score is preferred because it controls for the baseline difference in the participants' speed in responding (Cunningham, Preacher, and Banaji 2001).

An ANOVA was conducted with payment prime, time of purchase, and their interacting variables as predictors, and net score of the response latency as the dependent variable. The overall model was significant $(F(3,130)=15.15, p<$ $.0001)$, and there was a main effect of payment prime $(F(1$, $130)=44.52, p<.0001)$. A $t$-test indicated a significant difference between the response time difference score for the credit-primed participants $\left(M_{\mathrm{d}}=94.66\right.$ milliseconds $)$ and the cash-primed participants $\left(M_{\mathrm{d}}=-144.30\right.$ milliseconds): $t(132)=6.51, p<.0001$. Thus, our empirical evidence suggests that credit-primed participants respond faster to benefit words (relative to cost words) whereas the converse is true for the cash-primed people.

To explore this effect in more detail, we computed contrasts for the difference in response time for cost words and benefit words within payment prime condition. In the creditprime condition, response time for benefits $\left(M_{\mathrm{b}}=1,189.80\right.$ milliseconds) was faster than for costs $\left(M_{\mathrm{c}}=1,284.46\right.$ milliseconds, $p<.001)$. In the cash-prime condition, the converse pattern was observed, as expected. Response time for benefits $\left(M_{\mathrm{b}}=1,286.24\right.$ milliseconds) was slower than for costs $\left(M_{\mathrm{c}}=1,141.95\right.$ milliseconds, $\left.p<.0001\right)$. Contrasts between prime conditions comparing benefit and cost latencies between subjects are insensitive because idiosyncratic differences in response time and treatment by subject interactions are not controlled. However, we conducted these contrasts despite these limitations. The payment primes' simple main effect is not significant at the $p<.05$ level for either benefit or cost latencies. This null result reinforces the need to use difference scores to control for idiosyncratic variation when evaluating the payment prime effect when baseline measures of individual response latency are not available.

Mediation by Response Latency. We performed mediation analysis with reservation price as the dependent variable, payment prime as the predictor, and the difference score as the mediating variable. A series of regressions as per Baron and Kenny (1986) bore the following results. Regressing payment prime on the reservation price yielded a beta coefficient of $-3.49, p<.001$. Regressing payment prime on the difference score of the response latency yielded a beta coefficient of $-6.51, p<.0001$. The difference score of the response latencies predicted the reservation prices yielding a beta coefficient of $2.49, p<.05$. With payment and the mediating variable, difference score of response latencies, predicting reservation price, the beta coefficient of payment prime dropped down to $-2.57, p<.05$, suggesting a partial mediation. Using these values, a Sobel test was conducted for assessing the degree of mediation. The resulting Sobel test statistic $=-2.25, p<.01$, was statistically significant.

\section{Discussion}

We found that the difference in response times for benefits relative to costs for participants in the credit card condition was larger than for participants in the cash condition. This suggests that the credit card prime directed attention to product benefits. In addition, our data suggest that the temporal context for the product purchase, immediate versus later, did not influence the participants' processing of products' benefits or costs. In other words, our effects were replicated across near versus distant purchase contexts. In the first three studies, we demonstrated main effects of priming credit versus cash payment mechanisms. In our next study, we attempt to moderate the relationship between payment primes and subsequent evaluation using a dominated-decoys technique borrowed from the behavioral decision theory literature. 


\section{STUDY 4: MODERATION BY DOMINATED DECOYS}

The idea behind this study was to counter the biasing effects of cash and credit payment primes by shifting the attention of the participants to benefits or costs, respectively, using different decoys. If the payment prime effects operate by directing attention to either benefits (credit prime) or costs (cash prime) during product evaluation, any strong manipulation that shifts attention away from benefits in the credit prime condition or away from costs in the cash prime condition should moderate the payment prime effects. We use the findings from the research on decoy effects for the same. The research on asymmetrically dominated decoys (Huber, Payne, and Puto 1982; Simonson 1989) has found that introducing a decoy that is dominated on one attribute but not on another increases the choice share of the dominating option. While various complementary processes have been suggested to explain the decoy effect (see Wedell and Pettibone [1996] for a review), one major category of explanation is the perceptual focus framework (Dhar, Nowlis, and Sherman 2000). For example, a decoy dominated on the attribute of quality but not of price would shift attention to the quality attribute and thus help the choice share for the option that dominates on quality. We use this property of the decoys to test our proposed theoretical account and to moderate our previous findings.

In our experiment, we have three conditions: two conditions manipulate the attention on costs and benefits by introducing suitable decoys, and a third condition functions as control. In the control condition (without decoy), the pattern of results should be as follows. If credit cards prime attention to benefit considerations, participants should choose an option that is superior on benefits. However, if cash primes attention to cost considerations, participants should choose the option that is superior on costs. This pattern of results would represent a systematic replication of our effects on reservation price with an extension to choice as the key criterion. To test our conjecture of differential attention, we introduced two different decoys in the two manipulated conditions. One of the decoys was dominated on the products' cost dimensions and the other on benefits. If decoys make salient different product attributes (in this case costs vs. benefits), the attention directed to costs resulting from cash primes should be countered by the salience of benefits induced by a decoy dominated on benefits, and vice versa, thereby reversing or attenuating the effect of payment primes.

\section{Method and Design}

The study design was a 2 (money prime: cash vs. credit card) $\times 3$ (decoy: no decoy vs. decoy dominated on cost vs. decoy dominated on benefits) between participants. We conducted two pretests before running the study. One pretest was done to assess the importance of different attributes for an MP3 player on a 7-point scale $(1=$ not important at all, $7=$ very important). All the attributes that averaged over
4 were selected. These included aspects such as price, insurance, price of the MP3 files, price of the accessories, time taken to learn the operations, complexity of usage, battery life, compatibility with friends' MP3 players, quality of product, looks, whether friends like the product, prestige involved in owning the product, and operation simplicity. The participants further classified these as pertaining to costs or benefits. In a separate pretest, we asked the participants to rate the same attributes for three brands of MP3 players (Apple iPod, Microsoft Zune, and Sandisk Sansa) on an 11point scale $(0=$ low, $10=$ high). To enhance realism, the average ratings of the costs and benefits that we presented to participants as stimuli in the actual experiment were similar to the ratings provided by consumers in the pretest. We asked an unbiased rater (not familiar with the study hypothesis) to compare the classification of costs and benefits that were pretested. The rater found this classification similar to what had been used in study 3 .

Two hundred and fifty participants were randomly allotted across the six conditions and received partial study credit for participation. A sentence-unscrambling task, similar to previous studies, was adopted to prime cash or credit card concepts. In the next study (titled "Consumer Choice Study"), the participants were told that they would be provided with reviews from CNET.com about MP3 players and that they would have to choose one. To make the choice task realistic, the participants were further informed that there would be a lottery and that the lucky winner would get the chosen MP3 player. Next, the participants were told that each of the MP3 players that was reviewed had the following configuration: (1) $120 \mathrm{~GB}$ of storage, (2) could hold up to 30,000 songs, (3) could hold up to 150 hours of video, and (4) could hold up to 25,000 photos. Then, the participants were told that the CNET ratings that they were about to see were generated based on costs and benefits. For example, we provided them with some of the attributes that our pretest had generated (we included both monetary and nonmonetary costs, as also product related and other benefits). In the next screen, depending on their assigned condition, they saw ratings of either two MP3 players (iPod and Zune) or three MP3 players (iPod, Zune, and Sansa). On an 11-point rating scale $(0=$ lowest, $10=$ highest), Apple iPod was shown as having a rating of 8 on costs and 9 on benefits (i.e., relatively poor cost performance but excellent benefit performance) whereas Microsoft Zune was shown as having a rating of 6 on costs and 7 on benefits (i.e., lower cost, but also lower benefits than the iPod). Sansa was used as a decoy and, depending on whether it was a decoy dominated on costs or benefits, had different ratings (both costs and benefits were given a 7 rating for the decoy dominated on costs and 8 for the decoy dominated on benefits). In the dominated-on-costs condition, the decoy was inferior to the Zune with respect to costs. In the dominated-on-benefits condition, the decoy was inferior to the Apple iPod on benefits. The participants subsequently indicated their choices and answered questions related to demographic details. 


\section{Results}

Moderation by Dominated Decoys. The decoy took negligible choice share across two decoy conditions, and we found similar results with the third choice option (decoy) included in a multinomial logistic regression analysis. However, to maintain statistical equivalence (no decoy condition had two choices as opposed to decoy conditions that had three), we report the results with choice as a binary dependent variable. A logistic regression with money primes, decoy types, and their interacting variable as predictors and choice (iPod vs. Zune) as the dependent variable yielded a significant main effect of money $\left(\chi^{2}=14.35, p<.01\right)$, a significant main effect of decoy $\left(\chi^{2}=8.36, p<.01\right)$, which were qualified by a money prime $\times$ decoy interaction $\left(\chi^{2}\right.$ $=5.35, p<.05)$. The pattern of choices made in the creditprime and cash-prime conditions can be seen in table 1 .

As expected in the control condition (no decoy), there was a significant difference in the percent of people choosing iPod across cash versus credit card conditions $\left(\mathrm{P}_{\text {cash }}=25 \%\right.$, $\left.\mathrm{P}_{\text {credit }}=73.53 \%, \chi^{2}=16.48, p<.01\right)$. In the cash-prime condition, there was no significant difference in the choice of iPod across control (no decoy; $\mathrm{P}=25 \%$ ) and decoy dominated on costs $\left(\mathrm{P}=23.81 \% ; \chi^{2}=0.04, p>.1\right)$, whereas there was a significant difference in the choice of iPod across control (no decoy) and the decoy dominated on benefits (ddob; $\chi^{2}=22.08, p<.01, \mathrm{P}_{\text {control }}=25 \%$ vs. $\mathrm{P}_{\text {ddob }}$ $=71.05 \%)$. In the credit-card-prime condition, there was a significant difference between the control (no decoy; $\mathrm{P}=$ $73.53 \%)$ and decoy dominated on cost $\left(\mathrm{P}=36.36 \% ; \chi^{2}=\right.$ $12.57, p<.01)$ but no difference between control $(73.53 \%)$ and decoy dominated on benefits $\left(79.59 \% ; \chi^{2}=0.24, p>\right.$ $.1)$.

\section{Discussion}

In this study, we extend the findings of previous studies to the domain of consumer choice. Our results indicate that people choose a product superior on benefits when primed with credit concepts, but a product superior on costs is more likely to be chosen when consumers are primed with cash. Further, our results are supportive of our expectation that payment primes direct attention to different aspects of the products under consideration and consequently lead to different product evaluations and choices. By introducing an asymmetrically dominated decoy product into the consid- eration set, we are able to shift choices by redirecting attention away from primed benefits to costs or away from primed costs to benefits.

\section{GENERAL DISCUSSION}

\section{Overview}

Across four experiments, we demonstrate that consumers perceive and evaluate the same products differently when primed with credit cards as opposed to cash. Specifically, when credit concepts are activated, people attend more to benefit aspects of a product whereas when cash concepts are activated, people attend more to cost aspects of the product being considered (i.e., the costs associated with product acquisition and use). Contrary to previous research that assumes that products are perceived and evaluated similarly across different payment methods, we demonstrate that credit card primes increase attention to product benefits, thereby influencing product evaluation and reservation price. These same processes also lead consumers to choose a more attractive option more frequently when primed with credit concepts relative to cash concepts.

Shimp and Moody (2000) in their critique of Feinberg's conditioning explanation for the credit card premium suggested that the mechanism through which the credit card premium occurs needs further clarification. Other studies have attributed the increased willingness to spend due to making payments with a credit card as opposed to other payment mechanisms to memory differences and mental accounting effects related to deferral of the pain of payment when using credit cards (Prelec and Loewenstein 1998; Soman 2001) rather than to a conditioning process. Our research contributes materially to our understanding of the credit card premium and suggests another interesting process by which this premium may be elicited. However, our work also addresses a very fundamental question for consumer research by demonstrating that any factor that primes method of payment may alter consumers' evaluation of the products they are considering and even their choices among a set of products. Further, we are able to show that these effects can be obtained by priming concepts related to credit cards versus cash and that it is not necessary for a conscious decision to pay with credit or cash to have been made.

TABLE 1

STUDY 4: CHOICE PATTERN ACROSS CASH AND CREDIT PRIME CONDITION (\%)

\begin{tabular}{lccc}
\hline Choice & No decoy & $\begin{array}{c}\text { Decoy dominated } \\
\text { on costs }\end{array}$ & $\begin{array}{c}\text { Decoy dominated } \\
\text { on benefits }\end{array}$ \\
\hline $\begin{array}{l}\text { Cash-prime condition: } \\
\text { iPod }\end{array}$ & 25 & 23.81 & 71.05 \\
Zune & 75 & 76.19 & 28.95 \\
Credit-prime condition: & & 36.36 & 79.59 \\
iPod & 73.53 & 63.64 & 20.41 \\
Zune & 26.47 & & \\
\hline
\end{tabular}




\section{Theoretical Extensions}

We have proposed a priming explanation for consumers' tendency to spend more with credit cards than with cash. Further, we have gone beyond pain-of-payment explanations for the credit card premium to propose and demonstrate that credit card and cash payment mechanisms, when primed, can direct attention to different features of the products under consideration, thereby affecting product evaluations and choices as well. We rely in part on Prelec and Loewenstein's (1998) decoupling notion to explain why credit cards would have different associative networks from cash. However, it should also be noted that recent research has shown that credit card and cash payment methods vary in other ways as well. For example, while credit cards are more decoupled from the pain of payment than cash, they also differ in terms of physical form.

Raghubir and Srivastava (2008) argue that differences in physical form or appearance can cause payment mechanisms to be treated either as more like real money or more like "play" money, depending on their physical similarity to cash. Thus, a gift card may be similar to cash in terms of its close relation to the pain of payment (i.e., the cost of goods purchased immediately reduces their value); however, the difference in form makes the pain of payment less obvious, vivid, or transparent. Thus, both form and decoupling rely on differences in salience or transparency of pain of payment across payment mechanisms. In contrast, Zelizer (1994) would refer to the payment form argument as suggesting that various forms of money carry different meanings. It is this perspective that largely distinguishes our view from prior work on payment method effects. We argue that the ways in which credit cards are used over time leads to an enhanced salience of benefits relative to costs, while the converse is true for cash. In other words, products mean something different when evaluated by consumers primed with credit versus cash. Thus, we believe that the credit card premium is not due solely to differences in decoupling from pain of payment (i.e., reduced salience of costs) or to physical form, but in addition, the salience of product benefits is enhanced when thinking of paying with credit. We emphasize differences in the benefits aspect of the value equation, not just the cost aspects.

How strong is our evidence? Implicit in our use of the priming paradigm of Bargh and Chartrand (2000) is the assumption that credit card and cash stimuli activate related concepts in memory and that these concepts differ across payment mechanisms. In study 1 , the predicted pattern of errors in recall of benefits and costs was only partially supported. Recall errors in cost words were significantly lower in the cash-prime condition than the credit-prime condition, but recall errors in benefit words in the credit-prime condition did not differ significantly from the cash-prime condition. In study 2 , the pattern of word recognition results matched our expectations in that more cost words were recognized in the cash condition (relative to the credit condition) while more benefit words were recognized in the credit condition (relative to the cash condition). In study 3 , the mean latency differences for recognition of benefit and cost words differed across payment-prime conditions, as expected. Further, within the credit-prime condition, benefit words were recognized more quickly than costs words, while the converse was true in the cash-prime condition. Although based on a very insensitive test, the cross-prime contrasts revealed no significant differences in either benefit word latencies or cost word latencies. Thus, the evidence regarding the relative contribution of drawing attention to benefits or suppressing attention to costs to the well-documented credit-card premium is strongly suggestive but not conclusive.

We prefer a simple priming explanation for predicting payment mechanism effects. However, it remains to be determined whether or not the phenomenon we capture in terms of effects on costs and benefits could be subsumed within a higher order theoretical framework. One candidate framework is construal-level theory (Trope and Liberman 2010). It could be argued that credit payments are more psychologically distant and therefore construed at a more abstract psychological level than cash payments. In other words, mental accounting would be qualitatively different in that credit payments could be viewed as part of a monthly budget, while cash payments reflect the immediate feasibility of obtaining the desired product. However, psychological distance is related to the consumer's purchasing goal. If consumers have a goal of saving money, then cost becomes a defining, goal-relevant feature, and benefits may seem incidental to this abstract construal. However, if consumers have a goal of buying the highest quality product, then costs become a secondary, incidental feature, and benefits become more psychologically relevant. In other words, benefits and costs do not appear to map perfectly onto lowlevel and high-level psychological construal. Thus, while differences in the temporal coupling of credit and cash with the pain of payment make construal-level theory an intriguing general explanation for payment effects, we believe that there is still considerable work to be done to assess its viability in this context.

Our assumption, and one supported by Raghubir and Srivastava's (2008) suggestion that different schema may develop over time for various payment mechanisms, is that these activated concepts are more closely related to the benefits of products under consideration when credit cards are primed rather than cash. If learning is a key mechanism in the development of different associative networks related to credit cards and cash, it follows that the credit card premium may differ (or even be eliminated) for those consumers whose credit card use leads to traumatic consequences, what Bernthal, Crockett, and Rose (2005) have referred to as the "debtor's prison." In other words, any strong negative experiences with credit card use may fundamentally alter consumers' associative networks linked to that mode of payment. If this occurs, the effects we have observed may not be obtained. For these consumers whose credit card use has led to punishment in the marketplace, priming a credit card 
payment mechanism may make costs salient in a way that mirrors the effects induced by cash payments.

While we have provided evidence that attention is directed to different targets by cash and credit card primes, it is possible that the weights assigned to benefits and costs in evaluation and choice may also be affected. We do not have direct evidence that this differential weighting is occurring in our data. However, there are at least two possible mechanisms by which this effect could be obtained. A compelling argument could be made that, if perceptual salience of costs or benefits is enhanced by the payment primes, psychological salience as reflected in attribute weights is likely to be affected as well. For example, research has shown that a container's height is perceptually salient (i.e., attracts attention), and this perceptual salience leads consumers to overestimate the volume of a container (Folkes and Matta 2004). In other words, judgments of volume are biased by the salience of container height, an effect that clearly implies greater psychological salience or "weight." Another argument could be made for a compatibility effect (Fischer and Hawkins 1993; Shiv and Huber 2000). Activation of benefit concepts in response to a credit card prime corresponds more closely to benefit aspects of the product under consideration. Such compatibility may lead to an increase in the weights assigned to compatible features. Similar results would be expected for cash primes and compatibility with product costs.

\section{Substantive Implications}

Our work also has implications for public policy and consumer education that future research could address. For another example, consider the case of new technologically advanced payment mechanisms that allow consumers to make payments without a lot of deliberation. While convenient, these mechanisms do not encourage consumers to deliberate over their spending behavior. For example, many online merchants allow the option of automatically debiting one's account without having to fill in the details of the purchase. This arrangement, ostensibly for the consumers' convenience, seems to offer an even more powerful disconnection of spending from payment. Once an account has been created, subsequent purchases could be made with no reference to payment mechanism at all. In other words, neither credit nor cash concepts would be primed. It's not certain what the impact of this arrangement would be; however, prior work has suggested that decoupling the pain of payment from the act of purchase tends to increase spending. Whether this effect would exceed the credit card premium is a question that must be left to future research. Certainly, marketing technology continues to present challenges to those interested in consumer education and welfare and can have dramatic and possibly unanticipated effects on the aggregate market basket of goods purchased.

It is provocative to consider the aggregate effects of the ubiquitous nature of credit card primes relative to cash primes in our marketplaces. Marketers, by constantly reinforcing the salience of credit-related concepts, may be af- fecting not just the amount of money consumers are willing to spend but also the nature of the goods and services that find their way into consumers' market baskets. For example, recent research has demonstrated that payment mechanism can also have implications for consumers' health. Paying with credit cards may increase the likelihood of indulgent choices that are less healthy compared to cash (Thomas, Desai, and Seenavasin 2011). This effect is likely to be magnified by the rapid movement away from cash to credit/ debit card purchasing. It is also possible that consumers primed with credit cards and related concepts may choose categories that are more attractive when making higher level resource allocation decisions, may choose more attractive or high-image products among substitutes, and may include brands strongly linked to benefits more frequently in their consideration sets. In sum, our research suggests that the effects of credit card stimuli go beyond increasing consumers' spending power and shifting consumption from the future to the present.

\section{REFERENCES}

Agresti, Alan (2002), Categorical Data Analysis, Hoboken, NJ: Wiley.

Anderson, John R. (1983), "Retrieval of Information from Long Term Memory," Science, 220 (April), 25-30.

Anderson, John R. and Bower H. Gordon (1973), Human Associative Memory, Washington, DC: Winston.

Bargh, John A. (2006), "What Have We Been Priming All These Years? On the Development, Mechanisms, and Ecology of Nonconscious Social Behavior," European Journal of Social Psychology, 36 (2), 147-68.

Bargh, John A. and Tanya L. Chartrand (2000), "The Mind in the Middle: A Practical Guide to Priming and Automaticity Research," in Handbook of Research Methods in Social and Personality Psychology, ed. Harry T. Reis and Charles M. Judd, New York: Cambridge University Press, 253-85.

Baron, Reuben M. and David A. Kenny (1986), "The ModeratorMediator Variable Distinction in Social Psychological Research: Conceptual, Strategic, and Statistical Considerations," Journal of Personality and Social Psychology, 51 (6), 1173-82.

Bernthal, Matthew J., David Crockett, and Randall L. Rose (2005), "Credit Cards as Lifestyle Facilitators," Journal of Consumer Research, 32 (June), 130-45.

Bodenhausen, Galen V. (1988), "Stereotypic Biases in Social Decision-Making and Memory: Testing Process Models of Stereotype Use," Journal of Personality and Social Psychology, 55 (5), 726-37.

Cunningham, William A., Kristopher J. Preacher, and Mahzarin R. Banaji (2001), "Implicit Attitude Measures: Consistency, Stability, and Convergent Validity," Psychological Science, 12 (2), 163-70.

Darley, John M. and Paget H. Gross (1983), "A Hypothesis-Confirmation Bias in Labeling Effects," Journal of Personality and Social Psychology, 44 (1), 20-33.

Dhar, Ravi, Stephen M. Nowlis, and Steven J. Sherman (2000), “Trying Hard or Hardly Trying: An Analysis of Context Effects in Choice," Journal of Consumer Psychology, 9 (4), 189-200.

Feinberg, Richard A. (1986), "Credit Cards as Spending Facilitating Stimuli: A Conditioning Interpretation," Journal of Consumer Research, 13 (December), 348-56. 
Fischer, Gregory W. and Scott A. Hawkins (1993), "Strategy Compatibility, Scale Compatibility, and the Prominence Effect," Journal of Experimental Psychology: Human Perception and Performance, 19 (3), 580-97.

Fitzsimons, Grainne M., Tanya L. Chartrand, and Gavan J. Fitzsimons (2008), "Automatic Effects of Brand Exposure on Motivated Behavior: How Apple Makes You 'Think Different," Journal of Consumer Research, 35 (June), 21-35.

Folkes, Valerie S., and Shashi Matta (2004), "The Effect of Package Shape on Consumers' Judgments of Product Volume: Attention as a Mental Contaminant," Journal of Consumer Research, 31 (September), 390-401.

Hirschman, Elizabeth C. (1979), "Differences in Consumer Purchase Behavior by Credit Card Payment System," Journal of Consumer Research, 6 (June), 58-66.

Huber, Joel, John W. Payne, and Christopher Puto (1982), “Adding Asymmetrically Dominated Alternatives: Violations of Regularity and the Similarity Hypothesis," Journal of Consumer Research, 9 (June), 90-98.

Hunt, James M., Renee A. Florsheim, Anindya Chatterjee, and Jerome B. Kernan (1990), "Credit Cards as Spending-Facilitating Stimuli: A Test and Extension of Feinberg's Conditioning Hypothesis," Psychological Reports, 67 (1), 323-30.

Laran, Juliano, Amy Dalton, and Eduardo Andrade (2011), "The Curious Case of Behavioral Backlash: Why Brands Produce Priming Effects and Slogans Produce Reverse Priming Effects," Journal of Consumer Research, 37 (April), 999-1014.

Lee, Angela Y., and Jennifer L. Aaker (2004), "Bringing the Frame into Focus: The Influence of Regulatory Fit on Processing Fluency and Persuasion," Journal of Personality and Social Psychology, 86 (2), 205-18.

Mendoza, Norma A. and John W. Pracejus (1997), "Buy Now, Pay Later: Does a Future Temporal Orientation Affect Credit Overuse?" in Advances in Consumer Research, ed. Merrie Brucks and Deborah J. MacInnis, Provo, UT: Association for Consumer Research, 499-503.

Mishra, Arul (2009), "Influence of Contagious versus Noncontagious Product Groupings on Consumer Preferences," Journal of Consumer Research, 36 (June), 73-82.

Mishra, Himanshu, Arul Mishra, and Dhananjay Nayakankuppam
(2006), "Money: A Bias for the Whole," Journal of Consumer Research, 32 (March), 541-49.

Prelec, Drazen and George Loewenstein (1998), "The Red and the Black: Mental Accounting of Savings and Debt," Marketing Science, 17 (Winter), 4-28.

Prelec, Drazen and Duncan Simester (2001), "Always Leave Home without It: A Further Investigation of the Credit-Card Effect on Willingness to Pay," Marketing Letters, 12 (1), 5-12.

Raghubir, Priya and Joydeep Srivastava (2008), "Monopoly Money: The Effect of Payment Coupling and Form on Spending Behavior," Journal of Experimental Psychology: Applied, 14 (3), 213-25.

Shimp, Terence A. and Margaret P. Moody (2000), "In Search of a Theoretical Explanation for the Credit Card Effect," Journal of Business Research, 48 (1), 17-23.

Shiv, Baba and Joel Huber (2000), "The Impact of Anticipating Satisfaction on Consumer Choice," Journal of Consumer Research, 27 (September), 202-16.

Simonson, Itamar (1989), "Choice Based on Reasons: The Case of Attraction and Compromise Effects," Journal of Consumer Research, 16 (September), 158-74.

Soman, Dilip (2001), "Effects of Payment Mechanism on Spending Behavior: The Role of Rehearsal and Immediacy of Payments," Journal of Consumer Research, 27 (March), 460-74.

Soman, Dilip and Amar Cheema (2002), "The Effect of Credit on Spending Decisions: The Role of the Credit Limit and Credibility," Marketing Science, 21 (Winter), 32-53.

Thomas, Manoj, Kalpesh Kaushik Desai, and Satheeshkumar Seenavasin (2011), "How Credit Card Payments Increase Unhealthy Food Purchases: Visceral Regulation of Vices," Journal of Consumer Research, 38 (June), 126-39.

Trope, Yaacov and Nira Liberman (2010), "Construal-Level Theory of Psychological Distance," Psychological Review, 117 (2), 440-63.

Wedell, Douglas H. and Jonathan C. Pettibone (1996), "Using Judgments to Understand Decoy Effects in Choice," Organizational Behavior and Human Decision Processes, 67 (3), 325-44.

Zelizer, Viviana A. (1994), The Social Meaning of Money: Pin Money, Paychecks, Poor Relief, and Other Currencies, Princeton, NJ: Princeton University Press. 
Copyright of Journal of Consumer Research is the property of Journal of Consumer Research, Inc. and its content may not be copied or emailed to multiple sites or posted to a listserv without the copyright holder's express written permission. However, users may print, download, or email articles for individual use. 